Editorial

\title{
Publishing Risks
}

\author{
Mogens Steffensen \\ Department of Mathematical Sciences, University of Copenhagen, Universitetsparken 5, DK-2100 \\ Copenhagen Ø, Denmark; E-Mail: mogens@math.ku.dk
}

Received: 17 February 2014 / Accepted: 17 February 2014 / Published: 21 February 2014

"What is complicated is not necessarily insightful and what is insightful is not necessarily complicated: Risks welcomes simple manuscripts that contribute with insight, outlook, understanding and overview"- a quote from the first editorial of this journal [1]. Good articles are not characterized by their level of complication but by their level of imagination, innovation, and power of penetration. Creativity sessions and innovative tasks are most elegant and powerful when they are delicately simple. This is why the articles you most remember are not the complicated ones that you struggled to digest, but the simpler ones you enjoyed swallowing.

If good articles are often relatively simple, why is it so difficult to write a good article? It is because the process of putting together pieces in a new way to discover new relevant connections and insight may be difficult, even though the new connections and insight in themselves are not necessarily so; because the process of telling an exciting story about the new connections and insight may be demanding, even when the story in itself is not necessarily so.

It happens sometimes that the scientific storyteller of even good scientific stories ends up being tired of and sorry about the story too early. After having told it once-or maybe even before that - it may not seem so exciting to the storyteller anymore. After having realized what comes out of putting together the pieces, the results seem obvious to the scientist and he wrongly concludes that it is also obvious to the rest of the world. This is where the scientist has to remind himself about his obligation to the scientific society and beyond. The insight he obtained in his creative process is not worth anything if he keeps the news to himself, perhaps because he finds it too simple in retrospect. He must force himself to communicate his insight to the rest of the world.

Sometimes, the rest of the world indeed finds the insight obvious, simple, gained before, and the scientist finds himself, conclusively, behind schedule. Sometimes, the rest of the world finds the marginally interesting result obtained not worth pursuing further because the long, involved, energy-consuming way it took to get there was just too much of an effort. Sometimes, the rest of the world finds the insight new and accessible, but simply useless. Much of this kind of work is published almost everywhere. Occasionally, however, the rest of the world finds that the insight gained is 
substantially new, comprehensible with an acceptable amount of effort, and relevant and important to the community. Such manuscripts are luckily also published in many journals.

All journals are hunting for the last type of evergreens. But hunting is a risky activity. You may miss the target, the animals may be dangerous, and you may end up with a different species than the one you went in search of. Publishing is risky. Risks strives to harvest the best-for its readership and for its authorship.

Publishing risks are typically thought of as something else. Things can go wrong in any business and the publishing business is no exception. But the nature of publishing risks is somewhat different from the nature of risks in other businesses. Legal risks appear in terms of Copyright infringement and, perhaps, defamation. Financial risks exist, as for any other business, in terms of poor cash flow balancing, although the structure of cash flows is specific to the branch. These risks should be managed, carefully and professionally, by the publisher. The other part of publishing risks, the hunting risks, is managed in cooperation between the publisher, the editor-in-chief, and the editorial board. It is a delicate business. Editors do not consciously perform a quantitative risk-return analysis when making decisions. But unconsciousness about the betting nature of the activity is also a pitfall. There are good bets and bad bets. The odds are not always the same. Authors and editors, place some good bets!

Skills matter. Good hunters harvest what they came for. As do good publishers and editors. I am delighted to work together with the long and strong list of extremely skillful members of the editorial board. We hope and believe that the readership and the authorship are pleased with the harvest. We do not claim that we, exclusively, aim for and hit articles with an absolutely optimal balance between sophistication, innovation, and forcefulness. But we are ambitious. And we promise to concentrate on innovation rather than complication. And we dare take some good bets. Because, after all: "what is complicated is not necessarily insightful and what is insightful is not necessarily complicated."

\section{Reference}

1. Steffensen, M. Surrounding Risks. Risks 2013, 1, 43-44.

(C) 2014 by the author; licensee MDPI, Basel, Switzerland. This article is an open access article distributed under the terms and conditions of the Creative Commons Attribution license (http://creativecommons.org/licenses/by/3.0/). 